\title{
$O$ cuidado medicamentoso à criança com HIV: desafios e dilemas de familiares cuidadores
}

\author{
The medication care to children with HIV: challenges and dilemmas of family caregivers \\ El cuidado medicamentoso al niño con VIH: desafíos y dilemas de familiares cuidadores
}

\author{
Antonio Marcos Tosoli Gomes', Ivone Evangelista Cabral" \\ 'Universidade Estadual de Rio de Janeiro. Faculdade de enfermagem. Rio de Janeiro, RJ \\ "Universidade Federal do Rio de Janeiro. Escola de Enfermagem Anna Nery. Rio de Janeiro, RJ
}

Submissão: $01 / 10 / 2008$

Aprovação: 26/02/2009

\section{RESUMO}

O cuidado medicamentoso a criança HIV/Aids é marcado por desafios e dilemas. Neste contexto, objetiva-se discutir as situações existenciais vivenciadas por cuidadores na implementação desse cuidado. Trata-se de um estudo Qualitativo desenvolvido segundo o Método Criativo e Sensível com 13 cuidadores atendidos em um ambulatório. Os dados foram coletados pela dinâmica do concreto e analisados pela análise de discurso. Percebe-se um processo de normalização dos medicamentos e destaca-se a não utilização de recursos lúdicos para a sua administração. Observa-se que o início do uso é dificultado pelos efeitos colaterais e que posteriormente surgem questionamentos quanto à necessidade do uso. Conclui-se Que o cuidado é permeado por preconceitos e estigmas e ressalta-se a importância do profissional enfermeiro como educador em saúde.

Descritores: Síndrome de Imunodeficiência AdQuirida; Enfermagem em saúde pública; Pesquisa Qualitativa.

\section{ABSTRACT}

The medication care to children with HIV/Aids is marked with challenges and dilemmas. In this context, the purpose of this study is to discuss on the existential situations lived by caregivers when administering that care. This is a qualitative study developed according to the Creative and Sensitive Method, with 13 caregivers seen at an outpatient clinic. The data were collected using the concrete dynamics and analyzed according to discourse analysis. It was observed there is a normalization process of the medications, and it is highlighted there is no use of recreational resources in the administration. It was also observed that starting the use is difficult due to the side effects and, later, Questions emerge regarding the need of using the medication. In conclusion, the care is permeated with prejudice and stigmas, and it is emphasized that nursing professionals have an important role as health educators.

Descriptors: Aceuired Immunodeficiency Syndrome; Public health nursing; Qualitative research.

\section{RESUMEN}

El cuidado medicamentoso al niño HIV/ SIDA está marcado por desafíos y dilemas. En este contexto, se objeta discutir las situaciones existenciales vivenciadas por cuidadores en la implementación de este cuidado. Se trata de un estudio cualitativo desarrollado según el Método Creativo y Sensible con 13 cuidadores atendidos en ambulatorio. Los datos fueron recogidos por la dinámica del concreto y analizados por el análisis del discurso. Se percibe un proceso de normalización de los medicamentos y se destaca la no utilización de recursos lúdicos para su administración. Se observa Que el inicio del uso está dificultado por los efectos colaterales y que posteriormente surgen cuestionamientos en cuanto a la necesidad del uso. Se concluye Que el cuidado está afectado por prejuicios y estigmas y se destaca la importancia del profesional enfermero como educador de la salud. Descriptores: Síndrome de Inmunodeficiencia AdQuirida; Enfermería en salud pública; Investigación cualitativa. 


\section{CONSIDERAÇÕES INICIAIS}

As crianças soropositivas para o HIV têm ganhado importância no contexto da epidemia em função de diversos fatores. O primeiro, pelo seu crescimento epidemiológico em decorrência do processo de feminização da síndrome observado nos últimos anos; o segundo, pelo aumento da sobrevida daquelas Que foram contaminadas através da transmissão vertical, chegando à adolescência e à fase adulta; e o terceiro, pelo sofrimento psíquico, emocional e moral dos familiares e/ou cuidadores, oriundo da presença objetiva da morte no seio familiar ou de um forte processo de culpabilização Quando se pode identificar a pessoa responsável pela transmissão da doença ${ }^{(1)}$.

Neste contexto, além da obrigatoriedade de fornecer sentido ao drama humano de se ver tocado pela Aids, necessita-se, ainda, de forma compulsória, manipular tecnologias estranhas ao cotidiano familiar. Dentre essas tecnologias Que começam a fazer parte da rotina, destaca-se o fármaco como um objeto repleto de sentidos e significados, Quais sejam, a de mantenedor da vida e afugentador da morte; de material caro e concedido por caridade; de direito alcançado através do sistema de saúde; ou de algo perigoso em Que se necessita de conhecimentos e práticas especiais para a sua manipulação ${ }^{(2)}$.

Seja como for, o fato é Que os familiares e/ou cuidadores de crianças HIV positivas vêem-se na situação de dar conta de diversos desafios simultâneos para Que estas mesmas crianças continuem vivas e tenham Qualidade de vida em seus dia-a-dias. Ao mesmo tempo, sentem-se obrigados a entenderem a linguagem científica das unidades de saúde, a serem sensíveis às demandas objetivas e subjetivas das crianças e a acompanharem nas sucessivas construções simbólicas que estes atores sociais fazem ao longo de seu crescimento e desenvolvimento e no seu contato com a patologia em si e com os fármacos utilizados nos tratamentos ${ }^{(2)}$.

Assim, define-se como objetivo deste estudo discutir as situações existenciais vivenciadas por familiares cuidadores na implementação da oferta dos medicamentos à criança HIV positiva, relacionando, ainda, o tempo de tratamento estabelecido com o processo de aceitação do fármaco apresentado pelo grupo infantil.

\section{METODOLOGIA}

Quanto ao desenho da pesquisa, a abordagem Qualitativa foi adotada para conduzir a produção e a análise de dados. Entre os métodos Qualitativos, optamos pelo criativo e sensível ${ }^{(3)}$ porQue privilegiou-se a crítica reflexiva e a estratégia da dinâmica grupal entre os participantes da pesquisa, levando-os a interagir e dialogar sobre suas vivências e experiências.

Destaca-se a utilização de Dinâmicas de Criatividade e Sensibilidade (DCS) inspiradas nas dinâmicas de grupo, como a linha axial do método, combinado às produções artísticas delas decorrentes ${ }^{(3)}$. No interior das DCS, acontecem a entrevista coletiva, a discussão de grupo e a observação participante, mediada pela crítica reflexiva freiriana típica do círculo de cultura $^{(4)}$, para produzir dados para pesquisa.

O cenário de estudo foi uma unidade de saúde ambulatorial, pública, universitária, do Município do Rio de Janeiro, de referência para o atendimento à criança HIV/AIDS e sua família. O grupo de pesquisa foi constituído por 13 familiares e/ou cuidadores de crianças com necessidades especiais de saúde, HIV positivas, em uso contínuo de terapia anti-retroviral (TARV) no domicílio. Para garantir o anonimato dos sujeitos, adotaram-se pseudônimos indicados por eles mesmos (Denise, Pratrícia, Zilda, Sonia, Joel, Soraia, Fabiana e Dimas) e a enunciação das crianças no discurso dos participantes foi marcada no texto em ordem alfabética de aparecimento (A., B., C., D. e E.).

Para a produção de dados, realizou-se a dinâmica do concreto com sete participantes, distribuídos em dois encontros no mês de novembro de 2004, nas dependências do Laboratório de Pesquisa e Tecnologia Educacional em Saúde da Criança (LAPTESC), do Núcleo de Pesquisa em Saúde da Criança da Escola de Enfermagem Anna Nery, Universidade Federal do Rio de Janeiro/Brasil. Os participantes da pesquisa responderam duas Questões geradoras de debate: (a) o que eu tenho feito para Que meu filho tome o remédio? (b) o Que ele ou ela sente depois Que toma o remédio?

A dinâmica do concreto inspira-se nos princípios do role play ${ }^{(1-3)}$, tendo como característica central a explicitação do cotidiano do familiar e/ou cuidador na implementação de alguma prática de cuidar. No estudo em tela, eles demonstraram e falaram sobre suas práticas no cuidado a criança HIV/AIDS em uso de TARV.

A implementação das dinâmicas aconteceu em cinco momentos distintos: (a) o acolhimento e apresentação do ambiente da pesQuisa; (b) a apresentação dos participantes do grupo e a explicação sobre o encontro; (c) a enunciação e a discussão das Questões geradoras de debate; d) a dramatização e análise individual; e (e) análise e validação coletiva das produções individuais e do role play.

Cada dinâmica foi gravada em audiotape e videotape, gerando um relatório Que se constituiu na fonte primária dos dados, após a transcrição em verbatim. Do corpus dos textos foram demarcadas as situações existenciais em uma série de Quadros analíticos procurando explicitar os mecanismos de produção de sentido utilizados pelos sujeitos em sua discursividade, abrangendo o seu dito e o não-dito, a partir do referencial teórico da análise de discurso. Os Quadros analíticos permitiram a codificação das dimensões e das temáticas, bem como a sua descodificação (formação de subtemas) e a recodificação (síntese da temática ou da dimensão) $)^{(3,4)}$.

Ressalta-se Que o projeto foi aprovado pelo comitê de ética da instituição onde os sujeitos da pesquisa faziam o seguimento ambulatorial das crianças (Protocolo 013/04 CEP/EEAN-HESFA).

\section{RESULTADOS E DISCUSSÃO}

A partir das diretrizes do Método Criativo e Sensível e dos princípios freirianos, o grupo de estudo codificou o oferecimento do medicamento como um tema recorrente em sua cotidianidade e com a Qual necessita deparar-se, como um desafio a ser enfrentado na implementação do cuidado à criança HIV positiva. Neste contexto, as ações referentes a este oferecimento foram abordadas pelos familiares-cuidadores, Quando falaram sobre a administração do anti-retroviral.

Marcos (buscando garimpar alguns outros detalhes, continuo): _E Quando você dá (referindo-me aos medicamentos)...você dá alguma água depois (do medicamento à A.)? 
Denise (então, responde): - Não, não dou nada. Ela já acostumou normalmente.

Marcos (Por saber do gosto dos medicamentos, pergunto):_Ela não sente o gosto ruim?

Denise: - Não sente, não!

Marcos (tentando confirmar uma impressão inicial de Que vários artifícios eram usados, pergunto): - $E$, antigamente você precisava usar alguma coisa? Usava suco, usava água, usava D. (marca de iogurte, utilizada pela familiar-cuidadora para dar o medicamento)?

Denise (continua, respondendo à pergunta): - Não, também não.

Desde novinha, Quando ela (A.) começou o tratamento, ela sempre tomou (o medicamento) normalmente. E eles não são ruins, tem um gostinho/... de fruta. Quando ela começou, ela usava o de abacaxi (deve ser o AZT, mas o Ministério da Saúde não disponibiliza medicamentos com este sabor artificial), aí agora foi mudando. Agora, os Que têm não é ruim.

A recorrência de ressignificação dos sabores de anti-retrovirais apresentou-se como uma Questão interessante, pois além de não ser descrito na literatura Que trata da adesão à terapia, parece significar um processo de ancoragem do medicamento ao cotidiano da criança, tornando-o familiar. Utilizar a terminologia ancoragem significa afirmar Que o cuidado medicamentoso é construído de forma aderida à cotidianidade da criança, visando causar-lhe o mínimo de estranhamento em sua implementação ${ }^{(5)}$. Esse processo se dá Quando o fármaco é consumido no interior dessa estratégia maior dos familiares-cuidadores, onde estão incluídos os contatos interpessoais e o próprio oferecimento do medicamento.

Marcos (não me sentindo satisfeito com as respostas, proponho uma teatralização maior):_Então, faz o seguinte... eu sou a A., então, eu estou lá brincando. Como é Que você faz? Você colocou o medicamento (no copinho), e eu estou lá brincando...(-)

Denise: - Aí, Quando dá a hora, né? Que ela toma às sete horas.../ aí eu chamo ela. Aí eu coloco/, mexo (o frasco do medicamento), boto (o medicamento) no copinho e vou dando a ela (A.).

Marcos: E como é Que você acorda ela?

Denise (então começa a falar do Que foi perguntado): Normalmente, é só falar/: - A., vamos de tomar o remédio...// Às vezes, se a gente esquecer e sair, ela já fica na rua:_Denise/ , tem que tomar o remédio sete horas. _Denise!/ Aí eu fico: Calma, já está Quase na hora! Aí/, às vezés, Quando eu lembro Que tem Que levar o remédio, paro/, dou a ela (A.)/, porque aí ela também já sabe Quando Que ela tem Que tomar.

A situação existencial presente demonstrou certo grau de normalização do cuidado medicamentoso no cotidiano existencial das crianças soropositivas por parte dos familiares-cuidadores, de modo Que as mesmas solicitem a sua realização, mantendo a rotina a Que estão submetidas ${ }^{(6)}$. Esse ponto apresenta-se como uma lacuna importante a ser discutida com os familiares-cuidadores e do Qual emerge dois tipos de posicionamentos.

$\mathrm{O}$ primeiro refere-se à implementação do cuidado, inclusive o medicamentoso, com a clareza da especificidade vivenciada no cotidiano existencial da criança soropositiva, o Que significa pensar o cuidado como algo inserido em um processo de formação identitária específica da criança com HIV. Nesse sentido, cabe ao familiar-cuidador inserir o medicamento como algo reconhecidamente essencial à vida, ou seja, é preciso Que a criança saiba objetivamente (porque já o sabe subjetivamente) Que possui uma doença Que pode ser fatal.

O segundo, baseando-se no ocultamento ${ }^{(7)}$, no silêncio ${ }^{(8)}$ e no silenciamento ${ }^{(9)}$ procura normalizar os cuidados necessários à síndrome, especialmente o medicamentoso, construindo situações de modo Que ela não seja explicitada e, de preferência, não seja percebida pela criança. Esse fato constitui-se, por si só, em uma nova modalidade de ocultamento.

Os participantes da terceira dinâmica assim se posicionaram acerca das estratégias de cuidados:

Soraia: - ele toma esse aqui (ddl) só à noite, duas horas depois Que ele jantou... ele jantou e duas horas depois eu dou o remédio/ porQue senão ele/... não come...

Joel (apontando para o ddI, pergunta a Soraia):_a senhora não pode misturar esse remédio com mais alguma coisa...

Soraia (responde à dúvida do Joel): - Não! Eu já dou a janta dele cedo e duas horas depois eu dou o remédio (ddI)//... às vezes ele já está até dormindo, eu acordo ele e dou ele... porQue a doutora disse Que não pode dar (perto da comida)...

Joel (interrompe a fala da dona Soraia e comenta): - junto com a comida... e nem com outro remédio...

Soraia: o outro remédio eu dou ele de manhã...

Joel: é... a senhora não pode dar junto com outro remédio... Soraia: Antes da escola...

Joel (interrompe de novo a Soraia): Esse rosa (ddI) não pode dar junto com o alimento!

Sônia (concorda e complementa): -É/... também dou antes do alimento.../ levanta, toma logo o remédio (ddl)...

Zilda (por sua vez, demonstra seguir um outro padrão): eu dou antes da comida..

Sônia: ...esse aqui (ddl) eu não posso dar junto com a comida...

O Ministério da Saúde ${ }^{(10)}$, com relação ao medicamento citado, contudo, recomenda a abstinência uma hora antes e duas horas depois da alimentação. Segue-se, assim, um protocolo mais rígido Que o oficial. Nesse caso, pode ter havido uma ressignificação do 
dito do profissional de saúde, pois é mais fácil guardar o mesmo intervalo de tempo, ou pode ser Que os profissionais já utilizem essa estratégia, considerando uma margem maior de segurança e evitando possíveis equívocos pelos cuidadores.

Outra Questão cotidiana influenciada pelas necessidades e exigências do ddl é o padrão de sono e repouso Que, em algumas situações, precisa ser alterado para Que o referido medicamento seja administrado. Por outro lado, o fato de oferecer o medicamento à criança dormindo permite Que, naturalmente, o jejum seja mantido após a sua ingestão, como destacado acima pelos próprios familiares-cuidadores.

Observa-se, de modo intenso, a organização dos discursos dos familiares-cuidadores pela paráfrase $\mathrm{e}^{(9-11)}$. Todos, no trecho discursivo e dialógico acima, parafrasearam enunciações do profissional de saúde Quanto às suas recomendações. Esse assunto parece ser frisado no âmbito da unidade de saúde, uma vez que, pelo menos três familiarescuidadores apontaram a sua necessidade com uma discursividade bastante semelhante entre si e abordando todas as facetas necessárias ao oferecimento adeQuado do medicamento (ddl).

A situação existencial não apontou dificuldades no Que tange à relação entre restrição alimentar e adesão à terapêutica instituída. Contudo, diversos autores ${ }^{(12,13)}$ apontam a associação desse fator com baixos níveis de adesão nos casos das doenças crônicas e/ou necessidade de uso contínuo do medicamento; Outras pesquisas ${ }^{(14,15)}$ Que estudaram a sua participação e particularidade no esQuema antiretrovitral, demonstrando Que a necessidade de manter períodos regulares e constantes de jejuns gera maiores tendências de nãoaderência ao tratamento, o Que justifica o desenvolvimento de estratégias que facilitam a inclusão dessa exigência no cotidiano das crianças, especialmente revendo horários de alimentação, das demais atividades e da ministração do próprio anti-retroviral.

A Fabiana passa a expor a situação:

Fabiana (fala mais alto e retoma a direção do debate, após minha intervenção): ... Ela (B.) tomava, não reclama... agora Que está Querendo rejeitar... agora Que ela ta tendo um probleminha e ta Querendo rejeitar. Dá um espaço de uma hora, né? Eu ficava em casa, botava tudo pra fora. No início que ela vomitava, né? Mas a respeito do remédio, ela me lembra até da hora do remédio. Boto o celular pra despertar: - mãe, mãe, oh o remédio.

A discursividade apresenta-se tensionada entre o passado e o presente para expressar, de forma comparativa, a realização do cuidado medicamentoso. Ao retornar ao início de sua implementação, refere os episódios de vômito como situações Que interferiram com o cuidado, enquanto no presente destaca o processo de rejeição da criança ao fármaco, embora ainda ressalte o seu envolvimento, através do não-esquecimento da hora da ingestão do anti-retroviral.

Apesar de uma aparente contradição, observa-se que a lembrança dos horários do medicamento não se opõe à recusa atual da criança. Nesse sentido, enQuanto a não-aceitação parece se constituir como uma reação da criança à obrigatoriedade cotidiana do uso, a lembrança mostra Que, possivelmente, encontra-se em uma fase de transição em Que a predisposição e a indisposição para a utilização do medicamento estão presentes, expressando-se em comportamentos ambíguos, Quais sejam, a lembrança do horário (predisposição) e a rejeição (indisposição).

Essa idéia de processo também está presente na discursividade da própria familiar-cuidadora Quando ela anuncia Que está Querendo rejeitar, utilizando o gerúndio para expressar o sentido construído $^{(9,11)}$. Isto indica a vivencia atual do processo, ou seja, o fato não está dado ou terminado.

O diálogo continua:

Marcos (tento validar uma informação dada em outra dinâmicas e pergunto): - É fácil dar/.. é mais difícil dar o medicamento Quando começa o tratamento, ou é mais difícil com o tempo dar o medicamento?

Fabiana (de novo reinicia o debate): - Pra mim, foi Quando eu comecei, porQue ela (B.) vomitava muito.

Os fatores Que interferiram na implementação do cuidado medicamentoso e o oferecimento do medicamento no momento da instituição da terapêutica farmacológica foram os seus efeitos colaterais, como a náusea e o vômito. Ressalta-se que esses efeitos eram intensos, pois são explicitados verbalmente através de adjunto adverbial de intensidade (muito).

Frente a isso, o Dimas expressa a sua opinião, explicitando uma vivência diferente da Fabiana:

Dimas (retoma a palavra e comenta): - É mais difícil com o tempo, porque ela sempre pergunta... Quando ela vai parar de tomar remédio, Quando que ela vai ficar boa. Eu tô preparando... Eu tô me preparando pra saber como Que eu vou discutir isso com ela.

Na discursividade do Dimas, o início do tratamento apresentase como um momento mais fácil, em função da formação imaginária construída pela criança de Que o medicamento deve ser utilizado por um tempo, sendo interrompido Quando se atingir a cura (ficar boa). Logo, a realização do cuidado medicamento torna-se mais difícil com o tempo, à medida Que não há sinal de sua interrupção. Deve-se destacar eue a discursividade do familiar-cuidador parece silenciar-se frente a estas Questões anunciadas pela criança sob seus cuidados, constituindo-se o silêncio como tema trágico e em uma forma de silenciamento.

A tragédia desse silêncio apresentou-se ao não permitir o diálogo como acontecimento na relação entre o familiar-cuidador e a criança, ao mesmo tempo em Que impediu a constituição de sentido, uma vez Que as suas perguntas ficaram sem respostas ${ }^{(8)}$. O silêncio apresentou-se, contudo, como uma situação incômoda também para o familiar-cuidador, Que se vê diante de algo Que terá de enfrentar, mas Que não sabe ainda como fazê-lo.

O silenciamento ocorreu no interdito imposto à discursividade através da preparação do pai ${ }^{(9)}$. Esse processo de preparação impede, na atualidade, a construção e a sedimentação de um espaço dialógico, no Qual a voz e as dúvidas da criança não sejam silenciadas.

Quando a discursividade do Dimas expõe essa situação limite o ter de contar para a criança o Que ela tem - apresenta-se constituída por incompletude, evitando dizer aQuilo Que ainda não consegue ser dito. A incompletude do pensamento verbal se deu justamente na palavra preparar, sendo este o grande desafio Que o 
próprio familiar-cuidador se impõe frente ao Quadro da síndrome. da necessidade de uso do medicamento e, conseqüentemente, da revelação do HIV/Aids para a criança, desvelando uma faceta do seu cotidiano que é, até hoje, desconhecida.

O fenômeno da influência do tempo na implementação do cuidado medicamentoso apresentou-se como uma temática recorrente nas formações discursivas dos diferentes sujeitos do estudo e, portanto, transversal a todo o processo discursivo produzido no âmbito das dinâmicas de criatividade e sensibilidade. Apresenta-se também recorrente na literatura, como pode ser visto em diversos estudos ${ }^{(14,16-17)}$.

Dessa maneira, à medida Que o tratamento anti-retroviral aumenta a sobrevida das crianças, aumenta também a necessidade de se incluir a criança no processo terapêutico e de melhorar a sua adesão à terapêutica ${ }^{(18)}$. Nesse ponto, ganham realce as estratégias elaboradas pelos familiares-cuidadores para a implementação do cuidado medicamentoso e o papel dos profissionais de saúde como mediadores de novos saberes e práticas Que permitam um nível satisfatório de condições de saúde, diretamente relacionadas ao processo de adesão.

A Fabiana retoma a palavra, aprofundando o assunto:

Fabiana (fala novamente sobre o assunto): - Minha filha só fala assim: - já acabou, mãe, o remédio? Acabou. Sabe? Mas aí..

Observam-se diferenças de Questionamentos entre as duas crianças, pois enquanto a primeira preocupa-se em saber Quando vai parar de usar o medicamento ou ficar boa, esta Questiona se o medicamento já acabou, o Que permite um espaço maior de negociação e um período mais seguro para a manutenção do silêncio, diferente da situação do Dimas.

Com relação a essas duas últimas situações existenciais, os familiares-cuidadores explicitaram Que, no que tange à temporalidade do uso do medicamento, duas Questões são importantes: no início, os efeitos colaterais prejudicaram a realização do cuidado medicamentoso; ao longo do tempo, a recusa da criança, em função do seu uso contínuo. Alguns autores ${ }^{(17)}$ apontam o consenso existente na literatura acerca do declínio da taxa de adesão aos tratamentos contínuos, o que se apresenta como fundamental no caso das crianças soropositivas Que não tem previsão de interrupção do tratamento.

Outros autores $^{(15,17)}$, por outro lado, referem Que boa adesão no início da terapia está relacionada a melhores níveis dessa atitude ao longo da terapêutica, o Que confere maior responsabilidade à ação profissional nos momentos mediatos e imediatos ao diagnóstico.

O exercício diário do oferecimento do medicamento apresentase como um dos principais desafios à sobrevida da criança soropositiva, como conseQüência do nível de adesão atingido e dos desafios enfrentados para a elevação desse nível ${ }^{(17)}$. A vivência do ocultamento $^{(7)}$, do silêncio ${ }^{(4)}$ e do silenciamento ${ }^{(9)}$ torna esse cotidiano mais complexo à medida Que não há explicitação dos motivos pelos
Quais o medicamento é ingerido e nem diálogo acerca do período de tempo em Que deverá ser consumido.

Esse oferecimento é perpassado por Questões concretas relacionadas ao fármaco e às suas características, assim como de outras relativas à individualidade dos sujeitos e à sua dimensão subjetiva. O profissional de saúde deve estar atento a este cruzamento como forma de problematização do cotidiano existencial junto aos familiares-cuidadores, dando conta da abrangência da situação ${ }^{(19)}$.

\section{CONSIDERAÇÕES FINAIS}

Pode-se observar Que os familiares cuidadores procuram gerar um ambiente cotidiano Que propicie uma normalização dos antiretrovirais, normalmente escondendo a condição soropositiva e trabalhando com o imaginário da criança (bem como com o próprio) na tentativa de tornar a sua ingestão como parte da rotina diária e normal da família. Por isso, o processo de ancoragem do sabor apresenta-se fundamental por se tratar de um atrativo para o público infantil e aceitável para um adulto ofertar, afastando a idéia de sofrimento, obrigação e imposição.

Ao mesmo tempo, percebe-se Que as crianças absorveram este imaginário como sendo próprio, lembrando do horário do medicamento e não reQuerendo nenhum jogo relacional Que as envolva para Que a ingestão do mesmo fosse realizada. No entanto, a dimensão temporal, especialmente aquela referente ao uso dos anti-retrovirais, mostra-se inversamente proporcional à idéia de normalidade de um cotidiano permeado pelos anti-retrovirais.

Ou seja, o uso continuado e ininterrupto desses fármacos desperta o interesse da criança na perspectiva Que ela não tem nada (e assim por Que tomá-los?) ou de Que ela nunca melhora (uma vez que nunca pára de ingeri-los), gerando uma ruptura na construção de um cotidiano Que tem a necessidade de se alicerçar no não dito e Que não permite espaços maiores para discussões (como discutir algo Que não se deseja a existência ou mesmo Que a negue constantemente?). Esse Quadro gera uma situação limite em Que os familiares cuidadores são desafiados a oferecerem uma resposta Que permita um maior nível de complexidade na relação entre os membros do núcleo familiar e Que propicie maior conforto, segurança e adesão ao tratamento, o Que não implica, necessariamente, na revelação diagnóstica.

Em função desses aspectos e, especialmente, pela tendência à cronificação da síndrome decorrente do aumento da sobrevida das crianças, o enfermeiro possui um importante papel na assistência a este público, englobando a prevenção de doenças oportunistas e a promoção de sua saúde. Neste contexto, a educação em saúde, especialmente em sua vertente problematizadora e freireana, apresenta-se como uma importante ferramenta no processo de empoderamento dos familiares cuidadores, aumentando a Qualidade de vida e o processo de adesão à terapêutica. 


\section{REFERÊNCIAS}

1. Gomes AMT, Cabral IE, Schilkowisky LB. Crianças com HIV/ Aids de uma unidade ambulatorial pública. Rio de Janeiro. Brasil, 2003: Conhecendo seu perfil. Rev Soc Bras Enferm Ped 2004; 4(2): 55-68.

2. Gomes AMT. Silêncio, silenciamento e ocultamento na terapia antiretroviral: desvelando o discurso dos cuidadores de crianças [tese]. Rio de Janeiro: Escola de Enfermagem Anna Néry, Universidade Federal do Rio de Janeiro; 2005.

3. Cabral IE, Gauthier IHM, Figueiredo NMA, Oliveira ICS. Aliança de saberes no cuidado e estimulação da criança-bebê: concepções de estudantes e mães no espaço acadêmico de enfermagem. Rio de Janeiro: Escola Anna Nery; 1999.

4. Freire P. Conscientização: Teoria e prática de libertação. São Paulo: Moraes; 1980.

5. Oliveira DC. A promoção da saúde da criança: análise das práticas cotidianas através do estudo de representações sociais [tese]. São Paulo: Faculdade de Saúde Pública, Universidade de São Paulo; 1996.

6. Wong DL. Impacto da doença crônica, incapacitante ou da morte sobre a criança e a família. In: Wong DL. Enfermagem Pediátrica: elementos essenciais à intervenção efetiva. Rio de Janeiro: Guanabara Koogan; 1999. p. 467-505.

7. Bakhtin M. Marxismo e filosofia da linguagem. Problemas fundamentais do método sociológico na ciência da linguagem. São Paulo: Hucitec; 1992.

8. Freire P. Pedagogia do oprimido. São Paulo: Paz e Terra; 1981.

9. Orlandi EP. Análise de discurso: princípios e procedimentos. Campinas: Pontes; 2001.
10. Ministério da Saúde (BR). Coordenação Nacional de DST/AIDS. Guia de Tratamento Clínico da Infecção pelo HIV em Crianças. Brasília (DF): Ministério da Saúde; 2004.

1 1. Pecheux M. Semântica e discurso: uma crítica à afirmação do óbvio. Campinas: Unicamp; 1997.

12. Ickovics RJ, Meisler WA. Adherence in Aids clinical trials: a framework for clinical research and care. I Clin Epidemiol. 1997; 50(4): 385-91.

13. Mehta S, Morre RD, Grahan NMH. Potential factors affecting adherence with HIV therapy. AIDS 1997; I I (4): 1665-70.

14. Senack M. Predicting antiviral compliance: physicians responsibilities vs patients rights. Journal of International association of Physicians in AIDS Care 1997;3(2): 45-8.

15. Eldred L. Adherence in the Era of Prothease Innibitors. John Hopkins AIDS Service 2004; 4;(6).

16. Stelmann P. HIV? sim! E agora? São Paulo: Escolas Profissionais Salesianas; 2005.

17. Jordan MS, Lopes JF, Okazaki E, Komatsu, CL, Nemes MIB. Aderência ao tratamento antiretroviral em AIDS: revisão de literatura médica. In: Teixeira PR, Paiva V, Shimma E, organizadores. Tá Difícil de Engolir? Experiências de antiretroviral em São Paulo. São Paulo: NEPAIDS; 2000. p 5-25.

18. Matilda LH, Marcopito LF. Aumento do tempo de sobrevida das crianças com Aids - Brasil. In: Ministério da Saúde (BR). Coordenação Nacional de DST/AIDS. Boletim Epidemiológico DST/AIDS. Brasília (DF): Ministério da Saúde; 2004. p. 20-48.

19. Machado ALG, Freitas CHA, Jorge MSB. O fazer do cuidador familiar: significados e crenças. Rev Bras Enferm 2007; 60(5): 530-4. 